ABR 2021

Núm. 23

\section{Explorador Social: la dada feta realitat}

\author{
Albert Esteve \\ Director i Investigador (CED)
}

\section{Pilar Zueras}

Investigadora a l'Institute for Social and Economic Research-ISER (U. Essex) $i$ Coordinadora de l'Explorador Social (CED)

\section{$\because \quad$ Equip de l'Explorador Social}

Les administracions públiques produeixen i publiquen regularment grans volums d'informació en forma de dades empíriques desagregades a diferents escales territorials. Malgrat això, l'accés a aquesta informació està limitat per la dispersió de les dades en diferents repositoris, la diversitat de formats i la disparitat de modalitats d'accés. Des del Centre d'Estudis Demogràfics (CED) hem impulsat un projecte per recopilar, harmonitzar i difondre dades geo-referenciades actuals i històriques sobre diferents temàtiques (ex. demografia, economia, política, medi ambient, societat). En aquest número de Perspectives Demogràfiques presentem l'Explorador Social: una infraestructura de dades per a les ciències socials creada per promoure i facilitar l'accés a la informació i, en darrera instància, explorar la realitat i el canvi social de la població espanyola, mitjançant la cartografia i la quantificació estadística. La plataforma es dirigeix principalment a la comunitat educativa i científica, a l'administració pública, al sector privat, als mitjans de comunicació i al públic en general.

\section{Introducció}

Espanya és una societat ben diversa al llarg de la seva geografia. La població no es distribueix de forma homogènia entre els seus 8.131 municipis com tampoc ho fan els conreus (Figura 1), l'activitat econòmica o les opcions polítiques dels seus electors. Les dades empíriques ajuden a representar simbòlicament aquesta diversitat. El sistema estadístic espanyol, amb l'Instituto Nacional de Estadística (INE) al capdavant, produeix i publica quantiosos volums de dades a diferents escales territorials i sobre una gran varietat de temes. Malgrat això, l'accés a aquesta informació està limitat per tres motius:

En primer lloc, les dades estan disperses en una gran varietat de repositoris i això en dificulta la comparació. Si bé l'INE fa una tasca important de producció i recopilació de dades, no tota la informació que produeixen les administracions públiques, o altres organismes, es canalitza a través d'aquest Institut.

En segon lloc, el format i les característiques de les dades no estan harmonitzats. La falta d'harmonització exigeix, als usuaris, una certa experiència en el tractament de dades, fet que dissuadeix als usuaris no experts.

En tercer lloc, l'accés a la informació és poc amigable. No sempre és possible visualitzar les dades en la seva totalitat. A vegades els canals d'accés a les dades són laberíntics i la manera de presentar-los no desperta la curiositat dels usuaris. La informació sobre les dades (metadades) solen encapçalar la presentació de la dada i això sol dissuadir a molts potencials usuaris. Malgrat els avanços realitzats pels organismes públics per facilitar l'accés, el tractament i la visualització de les dades, encara persisteix una important bretxa entre la dada i l'usuari, que les noves tecnologies poden mitigar, difonent la informació de manera amigable i interactiva, tal com realitzen les versions digitals dels diaris i altres plataformes sobre temes de gran actualitat (ex. contagis covid, resultats electorals).
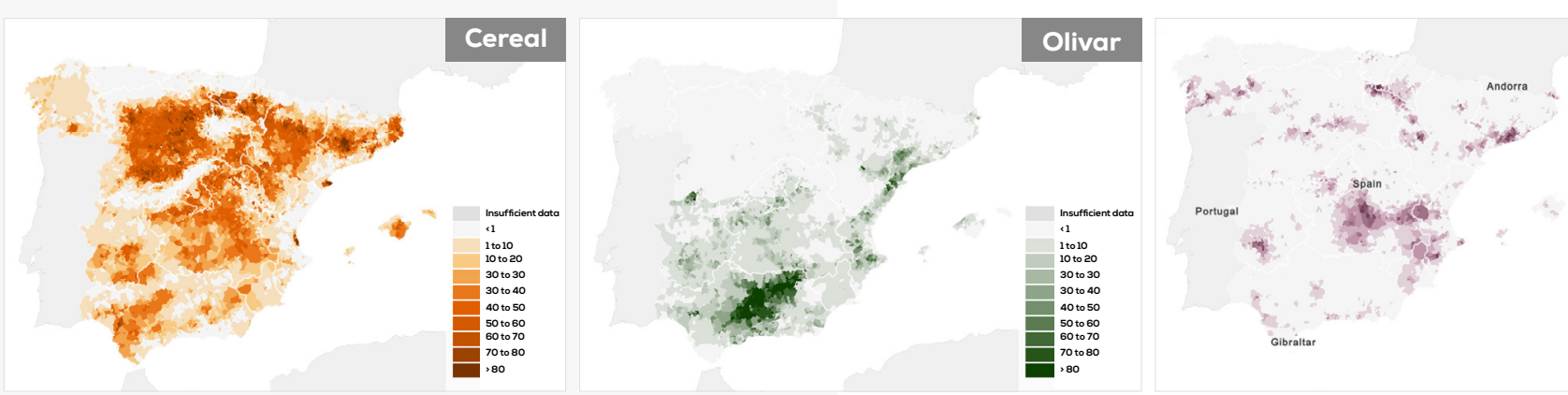

Figura 1. Proporció d'hectàrees conreades de cereal, olivera i vinya, a Espanya, per municipis. Nota: Explorador Social. Dades del Cens Agrari de 2009 (Instituto Nacional de Estadística). Selecció dels tres principals conreus: Cereal (6,3 milions d'ha conreades), Olivar (2,15 milions d'ha conreades), Vinya (o,8 milions d'ha conreades). L'avanç de resultats 2019 (Anuario del Ministerio de Agricultura, Pesca y Alimentación) dóna una caiguda del $-5 \%$ en cereal, augment del $21 \%$ en olivar, i del $10 \%$ en vinya. 
L'Explorador Social contribueix a reduir aquesta bretxa entre la dada i l'usuari: d'una banda, proporciona accés a les dades de manera àgil, flexible $i$ amigable $i$, per l'altra, ofereix la màxima cobertura temàtica, històrica i territorial. Amb aquest doble propòsit, el projecte té tres objectius específics:

Primer, recopilar i emmagatzemar el màxim d'informació en un únic repositori de dades, perquè els usuaris puguin comparar la informació, en el temps i en l'espai. L'interès i potencial d'ús d'una base de dades creix conforme augmenten i es diversifiquen els seus continguts. L'Explorador Social, s'alimenta primordialment de les estadístiques públiques (INE i instituts d'estadística autonòmics), però també dels registres administratius i dels propis càlculs demogràfics realitzats pel CED.

Segon, harmonitzar el format de les dades, la presentació i la documentació d'aquestes (metadades) per facilitar el seu accés, comprensió i consulta. Les dades recopilades són d'accés públic, oficials i contrastables. Això suposa harmonitzar les bases cartogràfiques, l'estructura de les bases de dades, les variables i les etiquetes i el contingut de les metadades.

Tercer, promoure l'accés a la informació mitjançant una potent eina de visualització i difusió de dades, que permeti a l'usuari seleccionar variables, observar el canvi en el temps, veure les dades a diferents escales, configurar mapes a mida, combinar diferents visualitzacions i descarregar la informació. L'èxit del projecte depèn de la forma en la què es difonin les dades. Aquesta ha de ser intuïtiva, directa $\mathrm{i}$ àgil. La plataforma desenvolupada per Social Explorer Inc. compleix aquests requisits.

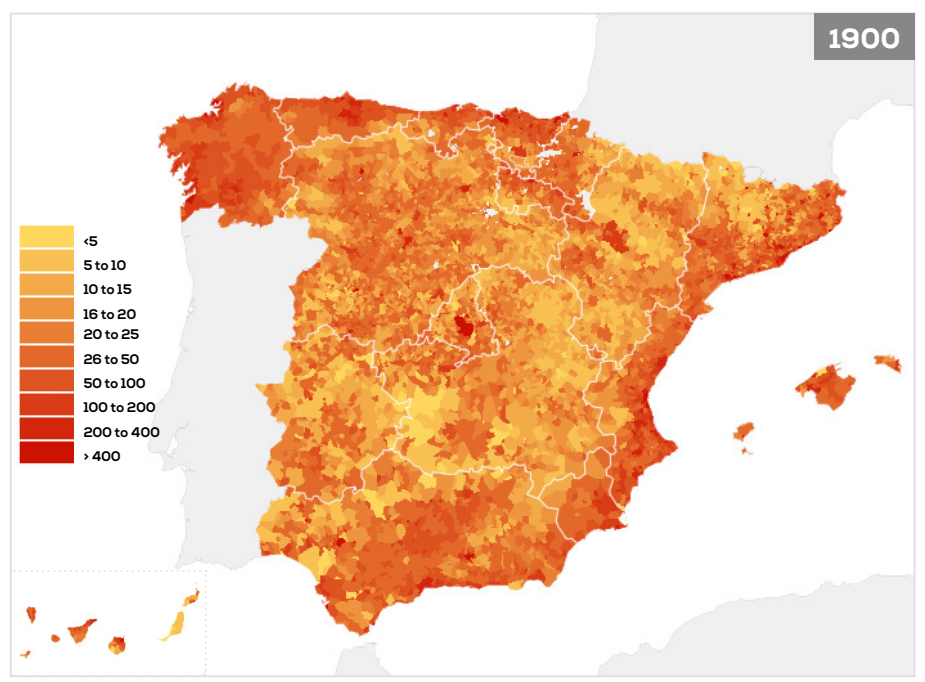

\section{Què és l'Explorador Social?}

L’Explorador Social és la implementació i adaptació, per a Espanya, de la plataforma Social Explorer dels Estats Units d'Amèrica. El projecte és una iniciativa del Centre d'Estudis Demogràfics en col-laboració amb Social Explorer Inc. i amb l'ajuda de la Fundació "la Caixa”. Després de dos anys de treball, l'Explorador Social és avui una realitat a "exploradorsocial.es". Hem desenvolupat una versió de la plataforma en castellà i un accés i sistema independent de gestió. El CED és responsable de la recopilació, harmonització i difusió dels continguts, i Social Explorer Inc. del manteniment i de les millores en el programari.

A data d'avui, l'Explorador Social conté més de 1470 variables, organitzades en 140 categories. Les variables originals s'organitzen en categories per facilitar l'accés (ex. població, habitatge, eleccions). Les dades estan desagregades a diferents escales, en funció de la variable i que van des de la secció censal (ex. padró i renda) fins a la Comunitat Autònoma. Per a la majoria de variables, la referència temporal de les dades va des de 1900 (ex. censos històrics) fins a l'actualitat. L'accés és obert però contempla la possibilitat que l'usuari pugui registrar-se per tenir una experiència personalizada de la plataforma (guardar variables, ubicacions, mapes o crear històries en format power point).

L'Explorador Social utilitza el mapa com a principal via d'accés a les dades. Els usuaris poden visualitzar les dades a diferents escales i saltar de l'una a l'altra fent un simple clic. Els usuaris poden compartir les seves cartografies a les xarxes socials. A més, poden seleccionar la tipologia de mapa (ex. trames, símbols, densitat),

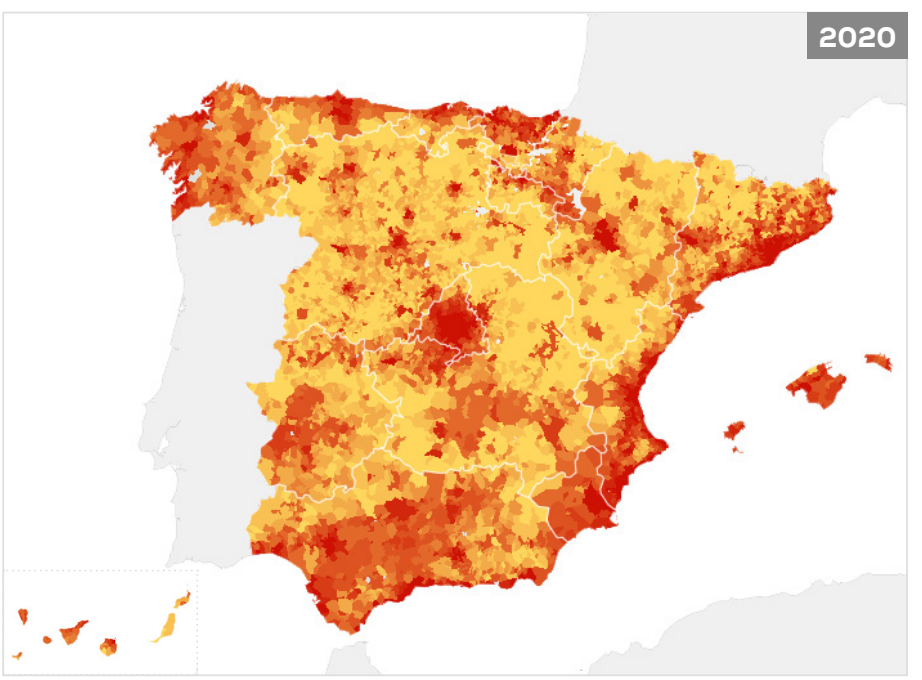

Figura 2. Densitat d'habitants per quilòmetre quadrat en els municipis espanyols, 190o i 2020. Nota: Explorador Social. Dades procedents del Cens de 1900 i del Padró Continu a 1 de gener de 2020. Els municipis han estat harmonitzats segons la divisió actual de 2011 seguint el mètode de l'Institut Valencià de Recerques Econòmiques-IVIE (Fundación BBVA i IVIE. Sèries homogènies de població, 2015). 
modificar la llegenda i les trames, colors i altres aspectes gràfics de la presentació.

L’Explorador Social és una infraestructura d'investigació dissenyada per a una àmplia diversitat d'usuaris. Docents i estudiants de secundària i universitaris, especialment de ciències socials, podran comptar amb una eina que complementi el seu ensenyament. Les administracions públiques tindran la informació centralitzada i personalitzada de les seves àrees de govern. Les empreses podran utilitzar les dades per informar-se en la presa de decisions. I els científics podran explorar, descarregar i processar la informació segons els convingui. A continuació il-lustrem la utilitat exploratòria i científica de l'Explorador Social amb dos exemples.

\section{Grans dades per a grans reptes}

Dècades de canvis demogràfics, socials i econòmics han impactat en la societat espanyola de múltiples formes i de manera desigual en el territori. Gràcies a les dades, podem quantificar la direcció i abast d'aquestes transformacions. Per il-lustrar les possibilitats de l'Explorador Social, hem seleccionat dos exemples relacionats amb el
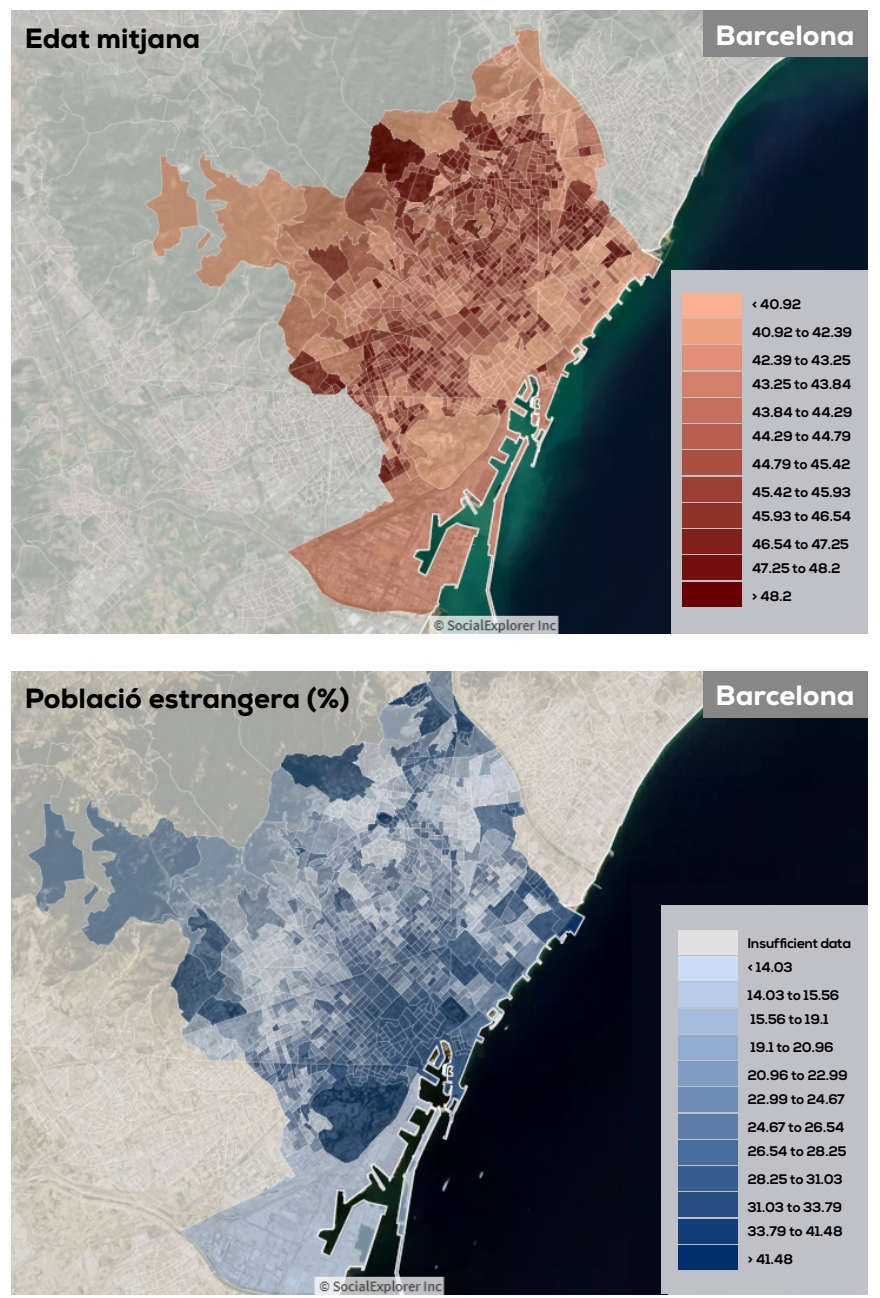

canvi demogràfic: la despoblació i la immigració internacional.

\section{LA DESPOBLACIÓ A ESPANYA, 1900 - 2020}

La despoblació (pèrdua gradual d'habitants), dels pobles i ciutats interiors d'Espanya és un tema de gran preocupació i actualitat política. La densitat d'habitants per quilòmetre quadrat (hab $\left./ \mathrm{km}^{2}\right)$ és un bon indicador per observar aquest fenomen. La Figura 2 mostra la densitat de població dels 8116 municipis espanyols (harmonitzats segons la divisió municipal de 2011) al 1900 i 2020. Les dades provenen del Cens de Població de 1900 i del Padró Municipal d'Habitants a 1 de gener de 2020.

En aquest període, la població d'Espanya ha crescut de 18,8 a 47,5 milions d'habitants i la densitat mitjana d'habitants per quilòmetre quadrat ha augmentat de 90 a 390. Malgrat això, el creixement no ha estat homogeni en el territori. Al 1900, hi havia 73 municipis a Espanya amb una densitat inferior a $5 \mathrm{hab} / \mathrm{km}^{2}$. Cent vint anys més tard, al 2020, el número de municipis amb una densitat inferior a $5 \mathrm{hab} / \mathrm{km}^{2}$ era de 2173. Les províncies amb el major nombre de municipis de baixa densitat són
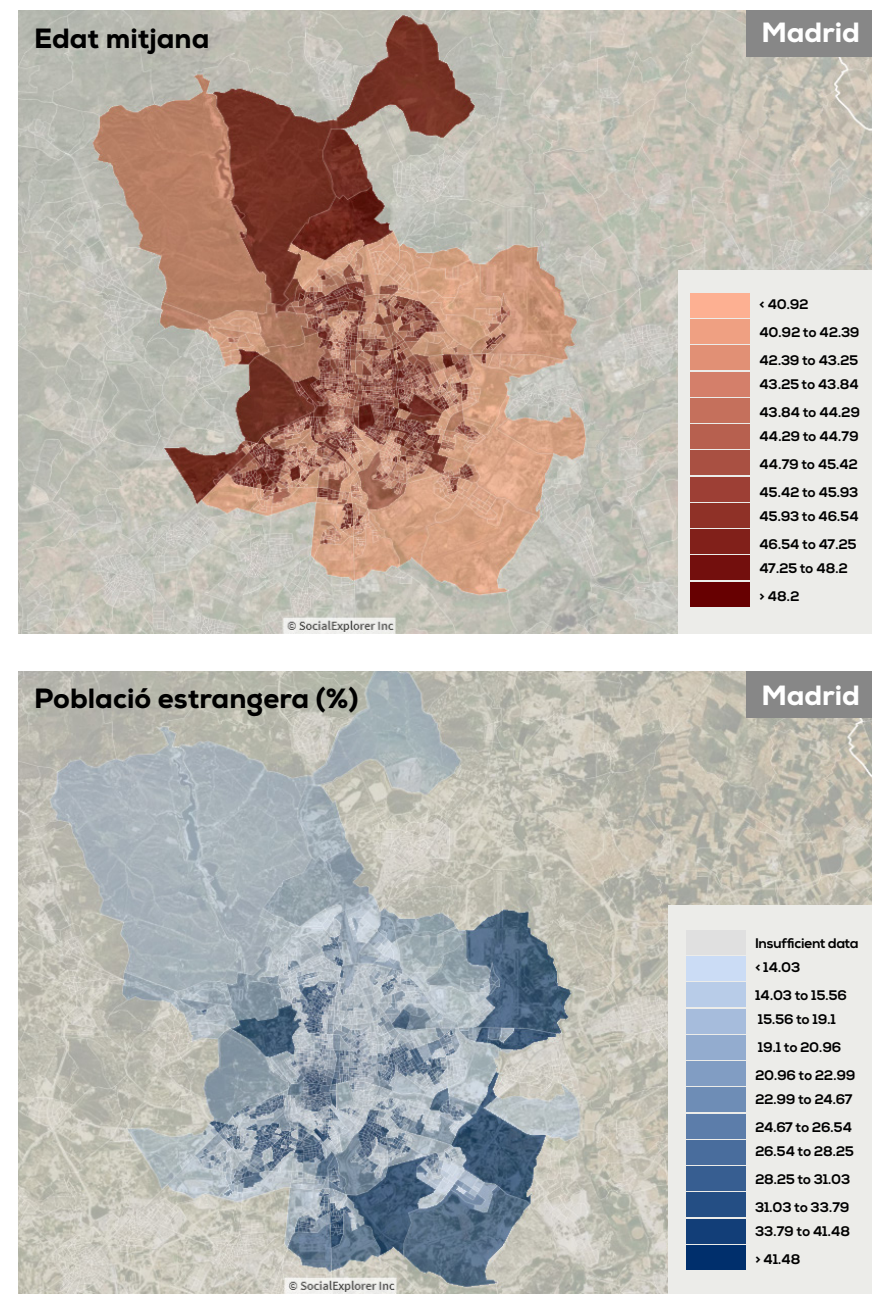
Guadalajara, Burgos, Terol, Salamanca i Sòria. En canvi, la densitat de població ha crescut significativament a les principals ciutats i àrees metropolitanes d'Espanya i en els municipis del litoral. Al 2020, la densitat de Madrid i Barcelona va assolir màxims històrics, amb 5.512 i $16.796 \mathrm{hab} / \mathrm{km}^{2}$ respectivament.

L'estudi de la despoblació a Espanya pot complementar-se amb altres variables d'interès com, per exemple, l'edat mitjana de la població, la proporció de llars unipersonals, la presència de determinats serveis en els municipis (ex. farmàcia, sucursal bancària, tipus d'accés a internet). Totes aquestes variables estan disponibles a l’Explorador Social.

\section{IMMIGRACIÓ INTERNACIONAL I EDAT MITJANA DE LA POBLACIÓ A MADRID I A BARCELONA}

Durant les darreres dues dècades, Espanya ha rebut més de 10 milions de persones estrangeres. La immigració ha contribuït al creixement i rejoveniment de la població espanyola. Però el seu impacte en el territori ha estat desigual. Madrid i Barcelona són els municipis que concentren més població estrangera d'Espanya, amb 788 i 462 mil persones respectivament. El $25 \%$ de la població, a les dues ciutats, és estrangera. L'edat mitjana de la població es troba al voltant dels 45 anys. La Figura 3 mostra la proporció de població estrangera i l'edat mitjana per secció censal, a Madrid i Barcelona, segons dades del Padrón Municipal de Habitantes a 1 de gener de 2020.

Madrid i Barcelona es divideixen en 2.443 i 1.068 seccions censals respectivament. El percentatge de població estrangera a les seccions censals oscil-la entre el 2,7 i el $62,6 \%$ a Madrid i entre el 4,6\% i el 83,2\% de la població a Barcelona. L'edat mitjana de la població a la ciutat de Madrid i a la de Barcelona és molt semblant, però la variabilitat censal és major en la primera. L'edat mitjana de les seccions censals a Madrid oscil-la entre els 26,7 anys la més jove, i els 65,7 la més envellida. A Barcelona, el rang de variació bascula entre els 34,6 i els 55,4 anys d'edat. El percentatge de població estrangera i l'edat mitjana de la població, en ambdues ciutats, estan directament relacionats, encara que l'associació és més forta a Barcelona. L'edat mitjana de la població sol ser més baixa on el percentatge d'immigrants és major. Malgrat això, a Madrid hi ha zones relativament joves amb poca població estrangera.

\section{Plans de futur}

Amb la col-laboració de la Fundació "la Caixa", l'aliança amb Social Explorer Inc. i el talent i perseverança del Centre d'Estudis Demogràfics, hem creat l'Explorador Social. El seu objectiu és recopilar, harmonitzar i difondre dades oficials i contrastades relatives a la societat espanyola i al seu territori. L'Explorador Social s'ha construït sobre una potent eina de visualització de dades basada en la reeixida experiència del Social Explorer Inc. Els objectius a consolidar en els pròxims mesos i anys són: l'actualització constant de la base de dades, la incorporació de nous continguts, la construcció de noves eines d'anàlisi (ex. canvis en el temps, informes a mida), la producció de material didàctic per a escoles i universitats i l'expansió a altres realitats territorials dins i fora d'Espanya. A la vegada, l'Explorador està pensat perquè productors de dades puguin compartir els seus continguts. Durant els propers mesos, i entre les novetats més importants, publicarem dades relacionades amb el medi ambient i les infraestructures de transports i dades històriques dels censos de població de 1900 a l'actualitat.

\section{Cita}

Esteve, A.; Zueras, P. i l'equip de l'Explorador Social (2021) "Explorador Social: la dada feta realitat". Perspectives Demogràfiques, 23: 1-4 (ISSN: 2696-4228). DOI: $10.46710 /$ ced.pd.cat.23

Equip de l'Explorador Social (per ordre alfabètic): Amand Blanes, Albert Esteve, Joan García, Amalia Gómez, Julián López, Antonio Medina, Teresa Menacho, Anna Turu i Pilar Zueras. Col-laboradors: Jordi Bayona, Pau Miret, Joaquín Recaño i Miquel Valls.

ISSN

ISSN 2696-4228

DOI

https://doi.org/10.46710/ced.pd.cat.23
Editors

Andreu Domingo i Albert Esteve (CED)

Correspondència dirigida a PilarZueras (pzueras@ced.uab.es)

Agraïments

A la Fundació "la Caixa" pel finançament aportat (acords LCF/ PR/GN18/50310008 i LCF/PR/CE20/50740004). A l'Instituto Nacional de Estadística i a la Secretaría General para el Reto Demográfico per facilitar laccés a les dades. I a tots els organismes que publiquen les dades dels quals es nodreix aquest projecte. La seva referència pot trobar-se en la secció de metadades de cada font seguint l'enllaç de les Taules.

A l'equip del Social Explorer, Andrew Beveridge i Ahmed Lacevic per la seva confiança i col-laboració en la realització d'aquest projecte. I especialment a Vedad Ramovic, Sejla Kumasin, Ed Parsons, Tanja Ibrahimpasic, Mersad Pasic i Nino Ćuso per la seva dedicació i ajuda.

Per la seva contribució, als estudiants de pràctiques que han participat en el projecte des del seu inici i fins avui: Mireia Cano,

Raúl Rezmes, Jennifer Bosch, Nicolás Aros, Laura Marbán, Mireia Olivares, Anna Montfort, Lara Morcillo, Osama Damoun, Jordi Calvo i Celia Fernández.

\section{Com citar l'Explorador Social}

Centre d'Estudis Demogràfics (2020)

Explorador Social: Versión 1.0 [dataset]. Barcelona. https://doi.org/10.46710/ced. es. 201820
Direcció Twitter @CED_explorador

Contacte Centre d'Estudis Demogràfics. Carrer de Ca n’Altayó, Edificio E2 Universitat Autònoma de Barcelona 08193 Bellaterra / Barcelona Espanya +34935813060 demog@ced.uab.es ced.uab.es/es/ 